\title{
引用論文の分散值を重み付けとして考慮したページランクアルゴリ ズムによる主要論文の抽出
}

\author{
Extraction of key literature based on PageRank algorithm considering \\ variance values of cited literatures as weighting
}

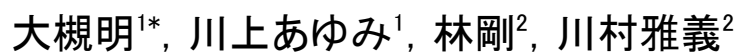 \\ Akira OTSUKI $^{1 *}$, Ayumi KAWAKAMI ${ }^{1}$, Takeshi HAYASHI ${ }^{2}$, Masayoshi KAWAMURA ${ }^{2}$ \\ 1 お茶の水女子大学 \\ Ochanomizu University \\ ₹112-8610 東京都文京区大塚2丁目1番1号 \\ E-mail: otsuki.akira@ocha.ac.jp \\ 2 東京大学
}

The University of Tokyo

干113-8656 東京都文京区弥生2-11-16東京大学工学部9号館320号室

*連絡先著者 Corresponding Author

学術俯瞰の分野における最近の研究動向は, 参考文献の引用分析により実現するサイテーショ ンマップが主流であり、ネットワーク構築やクラスタ化までの自動化はなされているが、各クラスタがど のような集団であるかの意味付けまでの自動化はなされておらず、専門家が手動で分析している現 状である.ゆえに、各クラスタの自動解釈を最終的な目的として, 本発表では各クラスタの主要論文 の自動抽出を目指す。具体的には、論文をノード、引用をエッジとする有向グラフと考え、各ノードに 発表年数を持たせたうえで、あるノードに入るエッジの元ノードの発表年数の分散を調べることでそ れぞれの重要度の計算を試みる。そして、それらの重要度を基に、時間軸を持つ可視化グラフの構 築を目指す。

Even though Citation Map has been in the mainstream of recent study trend in a field of academic landscape achieving the stage of automated clustering, the reality is that experts manually analyze semantic attachment about what kind of group each cluster is.

Therefore, we try to achieve an automated extraction of key literature of each cluster in the report, by setting automated interpretation of each cluster as the final purpose of the study.

キーワード: 学術俯瞰, 引用分析, データベース, ネットワーク分析

Keyword1, Science highangle, Citation analysis, Database, Network analysis 


\section{1 はじめに}

学術俯瞰の分野における最近の研究動向 は, 引用ネットワーク分析が主流であり, 自 動クラスタ化まで実現されている。しかし， クラスタリングにより同定された各領域の 特定や主要論文の自動抽出までは実現され てはいない.ゆえに, 本研究ではクラスタリ ングにより同定された各領域の主要論文を 自動で特定する手法について研究する. 具体 的には, 引用される側の論文の発表年数の分 散を調べ, その分散值をページランクアルゴ リズムに適応することにより各論文の重要 度を算出する。また，この重要度を基に、時 間軸を持つ可視化グラフの構築を目指す。

\section{2 先行研究}

学術俯瞰の分野において, Sma11[1]は, 被 引用数は上位 $1 \%$ の論文からなる共引用ネッ トワークを分析し, 科学分野で成長している 領域を追跡する方法を提案した。 また，松尾 [2]は, 図 1 のとおり, 引用ネットワークの 構築, 最大連結成分の取得, クラスタリング, 可視化を行うことで学術論文引用ネットワ ークを分析した。しかし，クラスタリングに より同定された各領域の特定や主要論文, 主 要研究者の抽出について自動化はなされて おらず，この部分は専門家が手動で分析して いるのが現状である。

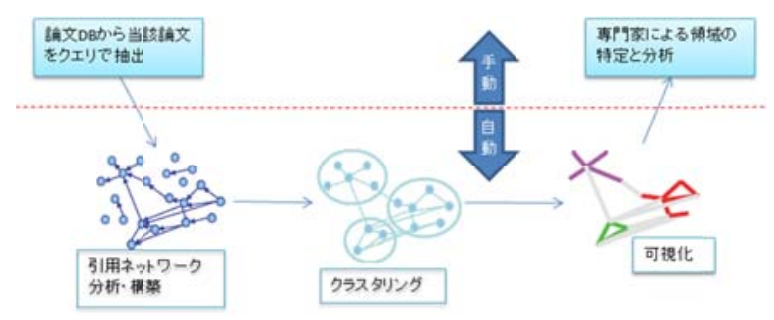

図 1 ネットワーク分析を応用した学術俯瞰の 手順

\section{3 提案手法}

前節の課題を解決するために, 本研究では 各領域の主要論文の自動抽出について考え る.引用件数が同じでも，「一時期に大量に 引用された」場合や、「長期間少しずつ引用 されている」場合などが考えられるため、従 来の引用分析だけでは、虫れぞれの重要度を 計算する事が難しい.ゆえに，本研究では， 上述のそれぞれの「場合」に対し，論文をノ ード、引用をエッジとする有向グラフと考え， 各ノードに発表年数を持たせたうえで，ある ノードに入るエッジの元ノードの発表年数 の分散を調べることでそれぞれの重要度の 計算を試みる、そして、それらの重要度を基 に, 時間軸を持つ可視化グラフの構築を目指 す.以下に全体の流れを記し，次節からその 詳細について述べる。

1. 論文 DB からキーワード（クエリ）検 索により論文数を絞る

2. 引用論文を中心にリスト化する.

3. 上記 2.のリスト加ら論文発表年数の 分散分析を行うことによって、各引用 論文に重み付けを行う

4. 上記 3.の重み付けページランクアル ゴリズムに適応して各引用論文の重 要度を算出する.

5. 重要度（ノード・エッジ）を基に可視 化

\section{2 論文DBからキーワード(クエリ)検索に よる論文数の絞り込み}

本研究では, 論文DBとしてSCOPUSを採用し た。「clustering」というクエリを用いて論 文数を絞った結果, 87,3919件の論文数に絞り 込まれた。 


\section{3 引用論文を中心にリスト化}

前節のリストは，各論文がどの論文を引用 しているかという並び順になっているが，そ れを各引用論文がいつ, どのような論文に引 用されているのかといった並び順に再リス 卜化する.

\section{4 論文発表年数の分散分析を行うこ とによる各引用論文の重み付け}

下記1）～3）により各引用論文の重み付け を行う。

1）ヒストグラムの最大值を抽出

最も引用数が多い年度を次の関数で抽 出し, MaxYearに格納する.

MaxYear $=\max \{y(x) / y(x):=y$ 年に参照された 回数\}

\section{2）引用期間の特定}

年度の古い年度から 1 年度毎に調べ, 最 初に見つかったMaxYearの10\%以上の引用 数の年度を引用がされ始めた開始年度と しStartYearに格納する. そして10\%以下の 引用数の年度になった時点で, その年度を last yearに格納する。そして論文が引用 され始めてから引用されなくなった年度 までの期間を次の式で求める.

Period := (LastYear +1$)-$ StartYear

また，図 2 のように，ヒストグラムの山が 複数存在する場合は, この作業を繰り返しそ れぞれPeriod0, $1 \cdots n$ に格納する.

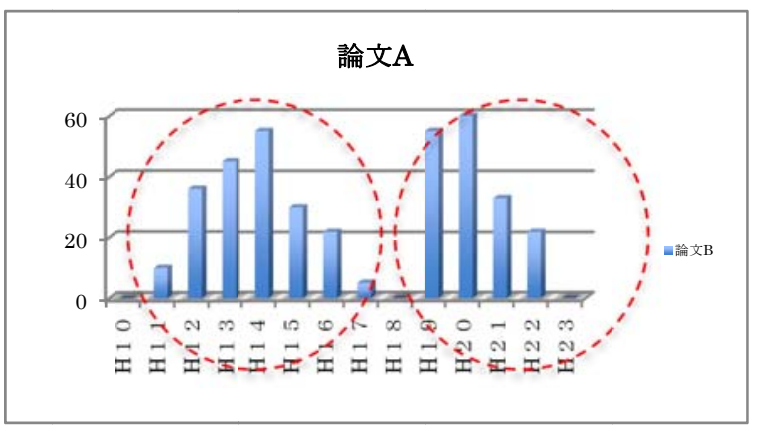

図 2 ヒストグラムの形が正規分布から外れてい るケース

3）ヒストグラムの分散（標準偏差）の算出 当該論文を引用する論文の発表年数の分 散（標準偏差）を調べることで当該論文がど のくらいの期間にわたって引用されている かについて調べる. なお, 標準偏差の一般的 な求め方は次のように表され, 求められた標 準偏差值はVarianceに格納する.

$$
\text { Variance }=\frac{\sum\left(x^{-} X^{-}\right)^{2}}{(n-1)}
$$

なお，図 2 のようにヒストグラムの形が正 規分布から明らかに外机ているようなケー ス（山がいくつもある様な場合）は， Period0, 1n.n分散（標準偏差）を算出し, それらの平均值をVarianceに格納する. そし て, Varianceを引用論文の重み付けの值とし て利用する.

\section{5 各引用論文の重要度の算出}

PageRankアルゴリズム [3]は，ハイパーリ ンク構造のような相互参照関係があるとき に、どのページがもつとも「重要」であるか を定量的に算出する手法である. 本研究では, このアルゴリズムを利用し, 各引用論文の重 要度の算出する. なお, この重要度の算出は 次のように表される。 
(1) 各論文は、固有の得点を持っている。 各引用もまた、固有の得点を持ってい る。

（2）ある論文X に対して，

・X の得点を $\mathrm{P}$ とする。

・Xが他論文から引用されている得点を それぞれ Variance,$\cdots$, Variance $_{n}$ と する。

・Xが他論文を引用している得点をそれ ぞれ $O_{1}, \cdots, O_{m}$ とする。

このとき、次が成り立つものとする。

Variance $_{1}+\cdots+$ Variance $_{n}=P$

$O_{1}=\cdots=O_{m}=\frac{p}{m}\left(=\frac{\sum_{i=1}^{n} \text { Variance }_{i}}{m}\right)$

すなわち、各論文に「流れ出す」引用の 得点の総和と、各論文から「流れ込む」引 用の得点の総和が等しくなるようにして、 その総和をその論文の得点と考え, この得 点が高いほど、その論文は重要であると考 える、そして，各論文から「流れ込む」引 用の得点計算にVarianceの值を適応するこ とにより, 各領域における主要論文の特定 を目指す。従来のアルゴリズムでは，「流れ 込む」引用が複数個あった場合, 得点は均 等に割り振られていたが, 本研究では Varianceの值が高いものにより多く「流れ 込む」と考え計算することで, 被引用年次 を反映した重要度を計算する。

\section{6 重要度を基に可視化}

前節で導出した重要度を元に引用ネット ワークとして可視化したものが図 3 である. 各ノードには論文名を表示しており, 前節の 重要度が高いほど,より大きなノードとして 表現される。なお，本ツールのことを HiAc( Highangle of Academic) と呼ぶ.

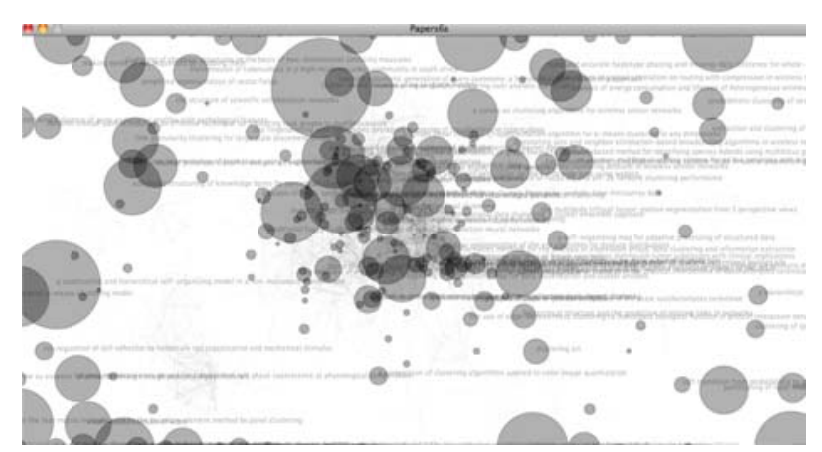

図 3 重要度に基づき可視化した例

\section{4 評価実験}

\section{1 専門家が手動で抽出した主要論文 との比較検証}

立堀 [4]らが2004年に発表した研究動向調 査報告は，I B Mの論文データベースを用い て, 1999年以降のソフトウエア・アーキテク チャ研究分野の動向を調査し, 主要な51論文 を手動で抽出したものである. 本評価実験で は，この専門家が手動で抽出した主要論文を どこまで自動で抽出できるかについて検証 する.

立堀らにおける51論文の抽出方法は, GoogleScholarを用いて年あたり引用数を求 め, その上位 40 論文を抽出している.この40 論文に加えて, 立堀らが特に重要と考えた国 際会議に絞ったうえで, ソフトウエア・アー キテクチャに関する11の論文を抽出してい る.また, 立堀らは, 定量的な研究動向評価 のために，独自の分類方式を採用している， 具体的には,ソフトウェア開発プロセスにお いて，ソフトウェア・アーキテクチャの果た す役割を, 次の $5 つ$ 役割のどれに着目して いるかによって51論文を分類しており，それ を図にしたものが図4で女る。

・[R]アーキテクチャへの要件 (Requirement) $\Rightarrow$ 様々な利害関係者のシステムへの要件 をアーキテクチャに反映する。 
・[M]アーキテクチャのメタモデル

(Metamode1)

＜compat>アーキテクチャの設計は, メタモデルに 基づいてアーキテクトが行う.

・[C］アーキテクチャの用いた利害関係者と のコミュニケーション (Communication) $\Rightarrow$ 全ての要件を満たすことができない場 合, 要件を調整するために, アーキテク チャを用いて利害関係者と交涉する。

・[S] アーキテクチャとシステム間の同期

(Synchronization)

$\Rightarrow$ 抽象的なアーキテクチャは, 実際に動く システムの実装に落とさなければなら ない，逆に，システムに変更があった場 合，それはアーキテクチャにも反映され るべきである。

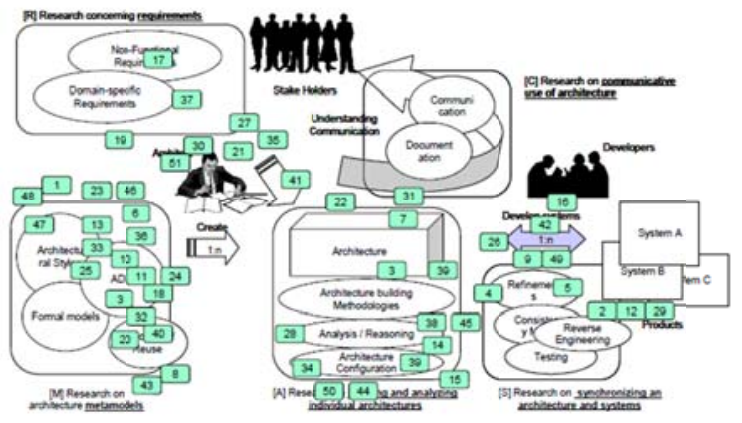

図4５1論文をソフトウエア・アーキテクチ ヤの 5 つの役割に分類したイメージ

立堀らの報告に対して, HiAcで同様に主 要論文を抽出したものが図5である，HiAcに おける論文抽出について述べる。 まず, 論文 DBとして SCOPUSを用いた。 そして, クエ リとして「Software Architecture」を，また， 年代として「1999年〜2004年」をそれぞれ設 定して論文を抽出した。なお，表 1 の 「SCOPUS」闌のとおり，51論文のうち，○ のついた 23 論文以外は，そもそもSCOPUSに は論文が存在しなかったため, 対象外として いる。 また，表1の論文番号を図4及び図5上
でも表記している，さらに，図4における 5 つの役割は, 定量的な研究動向評価のために 立堀らが独自に設定した分類方式であるた め, HiAcの場合（図5）では, 手動でクラス タの微調整を行った。

図5から，引用論文の分散值を重み付けと して考慮したページランクアルゴリズム (以 下「本アルゴリズム」という）によって可視 化した結果, 23 論文はどれも主要な論文とし て抽出されていた. 特に, 論文番号41-51は, 立堀らが主要な論文を手動で抽出したもの であり，その中でSCOPUSに存在したものは， 論文番号44-48であるが，それら全てを主要 論文として抽出できていた.

このように, 専門家が抽出した論文を本ア ルゴリズムによって分析することにより, 主 要な論文として自動で抽出することが可能 となる．ただ, $[\mathrm{R}]$ のクラスにおける緑の ノードなど, 立堀らが抽出していない論文も HiAcでは主要な論文として抽出していたが, これらの論文がどのような意味を持つもの かについては, 今後の課題として検討してい きたい.

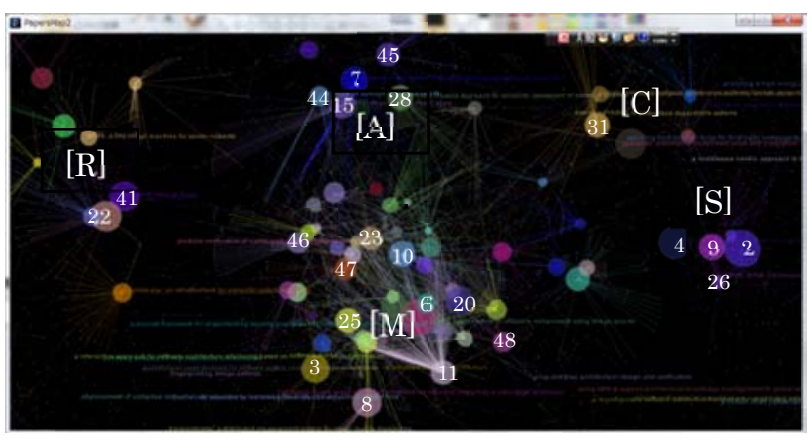

図5 51論文をHiAcで抽出したイメージ

表1 立堀らが抽出した51論文とSCOPUSで 抽出した19論文との対比表

\begin{tabular}{|c||c|c|c|c|c|}
\hline $\mathrm{N}$ & $\mathrm{C}$ & $\mathrm{Y}$ & Author & Title & $\mathrm{S}$ \\
$\mathrm{o}$ & $\mathrm{o}$ & $\mathrm{e}$ & & $\mathrm{C}$ \\
& $\mathrm{n}$ & $\mathrm{a}$ & & & $\mathrm{P}$ \\
& $\mathrm{f}$ & $\mathrm{r}$ & & & $\mathrm{U}$ \\
\hline \hline 1 & $\mathrm{W}$ & 2 & João Pedro Sousa, & Aura: An Architectural & $\mathrm{S}$ \\
\hline & $\mathrm{I}$ & 0 & & \\
\hline
\end{tabular}




\begin{tabular}{|c|c|c|c|c|c|}
\hline & $\begin{array}{l}\mathrm{C} \\
\mathrm{S} \\
\mathrm{A}\end{array}$ & $\begin{array}{l}0 \\
2\end{array}$ & David Garlan & $\begin{array}{l}\text { Framework for User } \\
\text { Mobility in Ubiquitous } \\
\text { Computing Environments }\end{array}$ & \\
\hline 2 & \begin{tabular}{l|l} 
\\
C \\
S \\
E \\
\end{tabular} & $\begin{array}{l}2 \\
0 \\
0 \\
2\end{array}$ & $\begin{array}{l}\text { Aldrich, J., } \\
\text { Chambers, C., } \\
\text { Notkin, D. }\end{array}$ & $\begin{array}{l}\text { ArchJava: Connecting } \\
\text { software architecture to } \\
\text { implementation }\end{array}$ & 0 \\
\hline 3 & $\begin{array}{l}\mathrm{I} \\
\mathrm{C} \\
\mathrm{S} \\
\mathrm{E}\end{array}$ & $\begin{array}{l}2 \\
0 \\
0 \\
0\end{array}$ & $\begin{array}{l}\text { Mehta, Nikunj R., } \\
\text { Medvidovic, } \\
\text { Nenad, Phadke, } \\
\text { Sandeep }\end{array}$ & $\begin{array}{l}\text { Towards a taxonomy of } \\
\text { software connectors }\end{array}$ & 0 \\
\hline 4 & \begin{tabular}{l|l} 
I \\
C \\
S \\
E \\
\end{tabular} & $\begin{array}{l}2 \\
0 \\
0 \\
3\end{array}$ & $\begin{array}{l}\text { Batory, D., } \\
\text { Sarvela, J.N., } \\
\text { Rauschmayer, A. }\end{array}$ & $\begin{array}{l}\text { Scaling step-wise } \\
\text { refinement }\end{array}$ & 0 \\
\hline 5 & \begin{tabular}{l|l|} 
I \\
C \\
S \\
E
\end{tabular} & $\begin{array}{l}1 \\
9 \\
9 \\
9\end{array}$ & $\begin{array}{l}\text { Nenad } \\
\text { Medvidovic, } \\
\text { David S. } \\
\text { Rosenblum, } \\
\text { Richard N. Taylor }\end{array}$ & $\begin{array}{l}\text { A Language and } \\
\text { Environment for } \\
\text { Architecture-Based } \\
\text { Software }\end{array}$ & $\times$ \\
\hline 6 & \begin{tabular}{l|l}
$\mathrm{I}$ \\
$\mathrm{C}$ \\
$\mathrm{S}$ \\
$\mathrm{E}$
\end{tabular} & $\begin{array}{l}2 \\
0 \\
0 \\
2\end{array}$ & $\begin{array}{l}\text { Dashofy, E.M., } \\
\text { Van Der Hoek, } \\
\text { A., Taylor, R.N. }\end{array}$ & $\begin{array}{l}\text { An infrastructure for the } \\
\text { rapid development of } \\
\text { XML-based architecture } \\
\text { description languages } \\
\end{array}$ & 0 \\
\hline 7 & \begin{tabular}{l|}
$\mathrm{I}$ \\
$\mathrm{C}$ \\
$\mathrm{S}$ \\
$\mathrm{E}$
\end{tabular} & $\begin{array}{l}1 \\
9 \\
9 \\
9\end{array}$ & $\begin{array}{l}\text { Kazman, Rick, } \\
\text { Barbacci, Mario, } \\
\text { Klein, Mark, } \\
\text { Carriere, } \\
\text { S.Jeromy, Woods, } \\
\text { Steven G. } \\
\end{array}$ & $\begin{array}{l}\text { Experience with } \\
\text { performing architecture } \\
\text { tradeoff analysis }\end{array}$ & 0 \\
\hline 8 & $\begin{array}{l}\mathrm{I} \\
\mathrm{C} \\
\mathrm{S} \\
\mathrm{E} \\
\end{array}$ & $\begin{array}{l}1 \\
9 \\
9 \\
9 \\
\end{array}$ & $\begin{array}{l}\text { Bowman, Ivan T., } \\
\text { Holt, Richard C., } \\
\text { Brewster, Neil V. }\end{array}$ & $\begin{array}{l}\text { Linux as a case study: Its } \\
\text { extracted software } \\
\text { architecture }\end{array}$ & o \\
\hline 9 & \begin{tabular}{l|l} 
\\
C \\
S \\
E
\end{tabular} & $\begin{array}{l}1 \\
9 \\
9 \\
9\end{array}$ & $\begin{array}{l}\text { Keller, Rudolf K., } \\
\text { Schauer, } \\
\text { Reinhard, } \\
\text { Robitaille, }\end{array}$ & $\begin{array}{l}\text { Pattern-based } \\
\text { reverse-engineering of } \\
\text { design components }\end{array}$ & $\mathrm{o}$ \\
\hline $\begin{array}{l} \\
0\end{array}$ & $\begin{array}{l}\mathrm{U} \\
\mathrm{M} \\
\mathrm{L}\end{array}$ & $\begin{array}{l}2 \\
0 \\
0 \\
0\end{array}$ & $\begin{array}{l}\text { Aler, R., Borrajo, } \\
\text { D., Camacho, D., } \\
\text { Sierra-Alonso, A. }\end{array}$ & $\begin{array}{l}\text { Reconciling the needs of } \\
\text { architectural description } \\
\text { with object-modeling } \\
\text { notations }\end{array}$ & 0 \\
\hline $\begin{array}{l}1 \\
1\end{array}$ & $\begin{array}{l}\mathrm{W} \\
\mathrm{I} \\
\mathrm{C} \\
\mathrm{S} \\
\mathrm{A}\end{array}$ & $\begin{array}{l}1 \\
9 \\
9 \\
9\end{array}$ & $\begin{array}{l}\text { Kruchten, P., } \\
\text { Selic, B., } \\
\text { Kozaczynski, W. }\end{array}$ & $\begin{array}{l}\text { Describing software } \\
\text { architecture with UML }\end{array}$ & 0 \\
\hline $\begin{array}{l}1 \\
2\end{array}$ & \begin{tabular}{l|l}
$\mathrm{E}$ \\
$\mathrm{C}$ \\
$\mathrm{O}$ \\
$\mathrm{O}$ \\
$\mathrm{P}$ \\
$\mathrm{P}$
\end{tabular} & $\begin{array}{l}2 \\
0 \\
0 \\
2\end{array}$ & $\begin{array}{l}\text { Jonathan Aldrich, } \\
\text { Craig Chambers }\end{array}$ & $\begin{array}{l}\text { Architectural Reasoning in } \\
\text { ArchJava }\end{array}$ & $x$ \\
\hline $\begin{array}{l}1 \\
3\end{array}$ & \begin{tabular}{l|}
$\mathrm{W}$ \\
$\mathrm{I}$ \\
$\mathrm{C}$ \\
$\mathrm{S}$ \\
$\mathrm{A}$
\end{tabular} & $\begin{array}{l}2 \\
0 \\
0 \\
1\end{array}$ & $\begin{array}{l}\text { Eric M. } \\
\text { Dashofy,André } \\
\text { van der } \\
\text { Hoek,Richard N. } \\
\text { Taylor } \\
\end{array}$ & $\begin{array}{l}\text { A Highly-Extensible } \\
\text { XML-Based Architecture }\end{array}$ & $x$ \\
\hline $\begin{array}{l}1 \\
4\end{array}$ & $\begin{array}{l}\mathrm{I} \\
\mathrm{C} \\
\mathrm{S} \\
\mathrm{E} \\
\end{array}$ & $\begin{array}{l}1 \\
9 \\
9 \\
9 \\
\end{array}$ & $\begin{array}{l}\text { Jean-Marc } \\
\text { DeBaud,Klaus } \\
\text { Schmid } \\
\end{array}$ & $\begin{array}{l}\text { A Systematic Approach to } \\
\text { Derive the Scope }\end{array}$ & $x$ \\
\hline $\begin{array}{l}1 \\
5\end{array}$ & \begin{tabular}{l|l} 
I \\
C \\
S \\
E \\
\end{tabular} & $\begin{array}{l}1 \\
9 \\
9 \\
9 \\
\end{array}$ & Bosch, Jan & $\begin{array}{l}\text { Product-line architectures } \\
\text { in industry: A case study }\end{array}$ & o \\
\hline $\begin{array}{l}1 \\
6\end{array}$ & \begin{tabular}{l|l} 
\\
C \\
S \\
E
\end{tabular} & $\begin{array}{l}2 \\
0 \\
0 \\
3\end{array}$ & $\begin{array}{l}\text { Anita Sarma, } \\
\text { Zahra Noroozi, } \\
\text { and André van der } \\
\text { Hoek } \\
\end{array}$ & $\begin{array}{l}\text { Palantír: Raising } \\
\text { Awareness among } \\
\text { Configuration Management } \\
\text { Workspaces } \\
\end{array}$ & $x$ \\
\hline $\begin{array}{l}1 \\
7\end{array}$ & \begin{tabular}{l|}
$\mathrm{W}$ \\
$\mathrm{I}$ \\
$\mathrm{C}$ \\
$\mathrm{S}$ \\
$\mathrm{A}$
\end{tabular} & $\begin{array}{l}2 \\
0 \\
0 \\
2\end{array}$ & $\begin{array}{l}\text { Shang-Wen } \\
\text { Cheng, David } \\
\text { Garlan, Bradley } \\
\text { Schmerl, } \\
\end{array}$ & $\begin{array}{l}\text { Using Architectural Style } \\
\text { as a Basis for System } \\
\text { Self-repair }\end{array}$ & $x$ \\
\hline $\begin{array}{l}1 \\
8\end{array}$ & $\begin{array}{l}\mathrm{U} \\
\mathrm{M} \\
\mathrm{L}\end{array}$ & $\begin{array}{l}1 \\
9 \\
9 \\
9\end{array}$ & $\begin{array}{l}\text { Fiadeiro, J.L., } \\
\text { Andrade, L.F. }\end{array}$ & $\begin{array}{l}\text { Interconnecting objects via } \\
\text { contracts }\end{array}$ & $x$ \\
\hline $\begin{array}{l}1 \\
9\end{array}$ & \begin{tabular}{l|l}
$\mathrm{P}$ \\
$\mathrm{F}$ \\
$\mathrm{E}$
\end{tabular} & $\begin{array}{l}2 \\
0 \\
0 \\
1 \\
\end{array}$ & $\begin{array}{l}\text { Jan Bosch, Gert } \\
\text { Florijn, Danny } \\
\text { Greefhorst, Juha }\end{array}$ & $\begin{array}{l}\text { Variability Issues in } \\
\text { Software Product Line }\end{array}$ & $x$ \\
\hline
\end{tabular}

\begin{tabular}{|c|c|c|c|c|c|}
\hline & & & Kuusela, & & \\
\hline \begin{tabular}{l|} 
\\
0
\end{tabular} & \begin{tabular}{|l|} 
I \\
C \\
S \\
E
\end{tabular} & $\begin{array}{l}1 \\
9 \\
9 \\
9\end{array}$ & $\begin{array}{l}\text { Dashofy, Eric M., } \\
\text { Medvidovic, } \\
\text { Nenad, Taylor, } \\
\text { Richard N. }\end{array}$ & $\begin{array}{l}\text { Using off-the-shelf } \\
\text { middleware to implement } \\
\text { connectors in distributed } \\
\text { software architectures }\end{array}$ & 0 \\
\hline $\begin{array}{l}2 \\
1\end{array}$ & \begin{tabular}{|l|}
$\mathrm{S}$ \\
$\mathrm{P}$ \\
$\mathrm{L}$ \\
$\mathrm{C}$ \\
\end{tabular} & $\begin{array}{l}2 \\
0 \\
0 \\
0\end{array}$ & Martin L. Griss & $\begin{array}{l}\text { Implementing Product-Line } \\
\text { Features By Composing } \\
\text { Component Aspects }\end{array}$ & $x$ \\
\hline $\begin{array}{l}2 \\
2\end{array}$ & $\begin{array}{l}\mathrm{F} \\
\mathrm{S} \\
\mathrm{E}\end{array}$ & $\begin{array}{l}2 \\
0 \\
0 \\
1\end{array}$ & $\begin{array}{l}\text { Uchitel, S., } \\
\text { Kramer, J., } \\
\text { Magee, J. }\end{array}$ & $\begin{array}{l}\text { Detecting implied scenarios } \\
\text { in message sequence chart } \\
\text { specifications }\end{array}$ & 0 \\
\hline \begin{tabular}{l|}
2 \\
3
\end{tabular} & \begin{tabular}{|l|} 
I \\
C \\
S \\
E \\
\end{tabular} & $\begin{array}{l}2 \\
0 \\
0 \\
0\end{array}$ & $\begin{array}{l}\text { Fielding, Roy T., } \\
\text { Taylor, Richard } \\
\text { N. }\end{array}$ & $\begin{array}{l}\text { Principled design of the } \\
\text { modern web architecture }\end{array}$ & 0 \\
\hline $\begin{array}{l}2 \\
4\end{array}$ & \begin{tabular}{l|} 
W \\
I \\
C \\
S \\
A
\end{tabular} & $\begin{array}{l}1 \\
9 \\
9 \\
9\end{array}$ & $\begin{array}{l}\text { Nenad } \\
\text { Medvidovic and } \\
\text { David S. } \\
\text { Rosenblum }\end{array}$ & $\begin{array}{l}\text { Assessing the Suitability of } \\
\text { a Standard Design Method } \\
\text { for Modeling Software } \\
\text { Architectures }\end{array}$ & $x$ \\
\hline $\begin{array}{l}2 \\
5\end{array}$ & \begin{tabular}{|l|}
$\mathrm{I}$ \\
$\mathrm{C}$ \\
$\mathrm{S}$ \\
$\mathrm{E}$ \\
\end{tabular} & $\begin{array}{l}1 \\
9 \\
9 \\
9\end{array}$ & $\begin{array}{l}\text { Di Nitto, } \\
\text { Elisabetta, } \\
\text { Rosenblum, David }\end{array}$ & $\begin{array}{l}\text { Exploiting ADLs to specify } \\
\text { architectural styles induced } \\
\text { by middleware } \\
\text { infrastructures }\end{array}$ & 0 \\
\hline $\begin{array}{l}2 \\
6\end{array}$ & \begin{tabular}{|l|}
$\mathrm{O}$ \\
$\mathrm{O}$ \\
$\mathrm{P}$ \\
$\mathrm{S}$ \\
$\mathrm{L}$ \\
$\mathrm{A}$
\end{tabular} & $\begin{array}{l}2 \\
0 \\
0 \\
1\end{array}$ & $\begin{array}{l}\text { Riehle, D., } \\
\text { Fraleigh, S., } \\
\text { Bucka-Lassen, D., } \\
\text { Omorogbe, N. }\end{array}$ & $\begin{array}{l}\text { The architecture of a UML } \\
\text { virtual machine }\end{array}$ & o \\
\hline $\begin{array}{l}2 \\
7\end{array}$ & \begin{tabular}{l|l}
$\mathrm{W}$ \\
$\mathrm{I}$ \\
$\mathrm{C}$ \\
$\mathrm{S}$ \\
$\mathrm{A}$
\end{tabular} & $\begin{array}{l}1 \\
9 \\
9 \\
9\end{array}$ & $\begin{array}{l}\text { Mark H. Klein, } \\
\text { Rick Kazman, } \\
\text { Len Bass, Jeromy } \\
\text { Carriere, Mario } \\
\text { Barbacci }\end{array}$ & $\begin{array}{l}\text { Attribute-Based } \\
\text { Architecture Styles }\end{array}$ & $x$ \\
\hline \begin{tabular}{l|}
2 \\
8
\end{tabular} & \begin{tabular}{l|} 
W \\
I \\
C \\
S \\
A
\end{tabular} & $\begin{array}{l}1 \\
9 \\
9 \\
9\end{array}$ & $\begin{array}{l}\text { Jeff Magee,Jeff } \\
\text { Kramer,Dimitra } \\
\text { Giannakopoulou }\end{array}$ & $\begin{array}{l}\text { Analyzing the behaviour of } \\
\text { distributed software } \\
\text { architectures: A case study }\end{array}$ & 0 \\
\hline $\begin{array}{l}2 \\
9\end{array}$ & \begin{tabular}{l|l}
$\mathrm{E}$ \\
$\mathrm{C}$ \\
$\mathrm{O}$ \\
$\mathrm{O}$ \\
$\mathrm{O}$
\end{tabular} & $\begin{array}{l}2 \\
0 \\
0 \\
3\end{array}$ & $\begin{array}{l}\text { Aldrich, J., } \\
\text { Sazawal, V., } \\
\text { Chambers, C., } \\
\text { Notkin. D. }\end{array}$ & $\begin{array}{l}\text { Language Support for } \\
\text { Connector Abstractions }\end{array}$ & $x$ \\
\hline $\begin{array}{l}3 \\
0\end{array}$ & $\begin{array}{l}\mathrm{G} \\
\mathrm{P} \\
\mathrm{C} \\
\mathrm{E}\end{array}$ & $\begin{array}{l}2 \\
0 \\
0 \\
2\end{array}$ & $\begin{array}{l}\text { Sandeep } \\
\text { Neema,Ted } \\
\text { Bapty,Jeff } \\
\text { Gray,Aniruddha } \\
\text { S. Gokhale }\end{array}$ & $\begin{array}{l}\text { Generators for Synthesis of } \\
\text { QoS Adaptation in } \\
\text { Distributed Real-Time } \\
\text { Embedded Systems }\end{array}$ & $x$ \\
\hline $\begin{array}{l}3 \\
1\end{array}$ & \begin{tabular}{l|l} 
I \\
C \\
S \\
E
\end{tabular} & $\begin{array}{l}2 \\
0 \\
0 \\
1\end{array}$ & $\begin{array}{l}\text { Kazman, R., } \\
\text { Asundi, J., Klein, } \\
\text { M. }\end{array}$ & $\begin{array}{l}\text { Quantifying the costs and } \\
\text { benefits of architectural } \\
\text { decisions }\end{array}$ & o \\
\hline $\begin{array}{l}3 \\
2\end{array}$ & $\begin{array}{l}\mathrm{L} \\
\mathrm{W} \\
\mathrm{I} \\
\mathrm{C} \\
\mathrm{S} \\
\mathrm{A}\end{array}$ & $\begin{array}{l}2 \\
0 \\
0 \\
1\end{array}$ & $\begin{array}{l}\text { Bridget } \\
\text { Spitznagel, and } \\
\text { David Garlan }\end{array}$ & $\begin{array}{l}\text { A Compositional Approach } \\
\text { for Constructing } \\
\text { Connectors }\end{array}$ & $x$ \\
\hline $\begin{array}{l}3 \\
3\end{array}$ & $\begin{array}{l}\mathrm{C} \\
\mathrm{E} \\
\mathrm{C} \\
\mathrm{O} \\
\mathrm{O} \\
\mathrm{P}\end{array}$ & \begin{tabular}{|l|}
2 \\
0 \\
0 \\
0
\end{tabular} & $\begin{array}{l}\text { Marcus Fontoura, } \\
\text { Wolfgang Pree, } \\
\text { Bernhard Rumpe }\end{array}$ & $\begin{array}{l}\text { UML-F: A Modeling } \\
\text { Language for } \\
\text { Object-Oriented } \\
\text { Frameworks }\end{array}$ & $x$ \\
\hline $\begin{array}{l}3 \\
4\end{array}$ & $\begin{array}{l}\mathrm{F} \\
\mathrm{S} \\
\mathrm{E}\end{array}$ & $\begin{array}{l}1 \\
9 \\
9 \\
9\end{array}$ & $\begin{array}{l}\text { Pascal Fradet, } \\
\text { Daniel Le } \\
\text { Métayer and } \\
\text { Michaël Périn }\end{array}$ & $\begin{array}{l}\text { Consistency Checking for } \\
\text { Multiple View Software } \\
\text { Architectures }\end{array}$ & $x$ \\
\hline $\begin{array}{l}3 \\
5\end{array}$ & $\begin{array}{l}R \\
E\end{array}$ & $\begin{array}{l}2 \\
0 \\
0 \\
2\end{array}$ & $\begin{array}{l}\text { Jon G. Hall } \\
\text { Michael Jackson } \\
\text { Robin C. Laney } \\
\text { Bashar Nuseibeh }\end{array}$ & $\begin{array}{l}\text { Relating Software } \\
\text { Requirements and } \\
\text { Architectures using } \\
\text { Problem Frames }\end{array}$ & $x$ \\
\hline $\begin{array}{l}3 \\
6\end{array}$ & \begin{tabular}{l|l}
$\mathrm{S}$ \\
$\mathrm{P}$ \\
$\mathrm{L}$ \\
$\mathrm{C}$
\end{tabular} & \begin{tabular}{|l}
2 \\
0 \\
0 \\
2
\end{tabular} & Jan Bosch & $\begin{array}{l}\text { Maturity and Evolution in } \\
\text { Software Product Lines: } \\
\text { Approaches, Artefacts and } \\
\text { Organization }\end{array}$ & $x$ \\
\hline $\begin{array}{l}3 \\
7\end{array}$ & $\begin{array}{l}\mathrm{R} \\
\mathrm{E}\end{array}$ & $\begin{array}{l}1 \\
9 \\
9 \\
9\end{array}$ & John Grundy & $\begin{array}{l}\text { Aspect-oriented } \\
\text { Requirements Engineering } \\
\text { for Component-based } \\
\text { Software }\end{array}$ & $x$ \\
\hline
\end{tabular}




\begin{tabular}{|c|c|c|c|c|c|}
\hline & & & & Systems & \\
\hline $\begin{array}{l}3 \\
8\end{array}$ & $\begin{array}{l}\mathrm{F} \\
\mathrm{S} \\
\mathrm{E}\end{array}$ & $\begin{array}{l}2 \\
0 \\
0 \\
1\end{array}$ & $\begin{array}{l}\text { Nima Kaveh, } \\
\text { Wolfgang } \\
\text { Emmerich }\end{array}$ & $\begin{array}{l}\text { Deadlock detection in } \\
\text { distribution object systems }\end{array}$ & $x$ \\
\hline $\begin{array}{l}3 \\
9\end{array}$ & $\begin{array}{l}\mathrm{F} \\
\mathrm{S} \\
\mathrm{E}\end{array}$ & $\begin{array}{l}1 \\
9 \\
9 \\
9\end{array}$ & $\begin{array}{l}\text { Michel } \\
\text { Wermelinger, José } \\
\text { Luiz Fiadeiro }\end{array}$ & $\begin{array}{l}\text { Algebraic software } \\
\text { architecture reconfiguration }\end{array}$ & $x$ \\
\hline $\begin{array}{l}4 \\
0\end{array}$ & \begin{tabular}{l|}
$\mathrm{I}$ \\
$\mathrm{C}$ \\
$\mathrm{S}$ \\
$\mathrm{E}$ \\
\end{tabular} & $\begin{array}{l}2 \\
0 \\
0 \\
3 \\
\end{array}$ & $\begin{array}{l}\text { Spitznagel, B., } \\
\text { Garlan, D. }\end{array}$ & $\begin{array}{l}\text { A compositional } \\
\text { formalization of connector } \\
\text { wrappers }\end{array}$ & O \\
\hline $\begin{array}{l}4 \\
1\end{array}$ & $\begin{array}{l}\mathrm{F} \\
\mathrm{S} \\
\mathrm{E}\end{array}$ & $\begin{array}{l}2 \\
0 \\
0 \\
4\end{array}$ & $\begin{array}{l}\text { Uchitel, S., } \\
\text { Chatley, R., } \\
\text { Kramer, J., } \\
\text { Magee, J. }\end{array}$ & $\begin{array}{l}\text { System architecture: The } \\
\text { context for scenario-based } \\
\text { model synthesis }\end{array}$ & $x$ \\
\hline $\begin{array}{l}4 \\
2\end{array}$ & $\begin{array}{l}\mathrm{F} \\
\mathrm{S} \\
\mathrm{E}\end{array}$ & $\begin{array}{l}2 \\
0 \\
0 \\
4 \\
\end{array}$ & $\begin{array}{l}\text { Zhang, X., Young, } \\
\text { M., Lasseter, } \\
\text { J.H.E.F. }\end{array}$ & $\begin{array}{l}\text { Refining code-design } \\
\text { mapping with flow analysis }\end{array}$ & $x$ \\
\hline $\begin{array}{l}4 \\
3\end{array}$ & \begin{tabular}{l|} 
I \\
C \\
S \\
E
\end{tabular} & $\begin{array}{l}2 \\
0 \\
0 \\
4\end{array}$ & $\begin{array}{l}\text { Hasselbring, W., } \\
\text { Reussner, R., } \\
\text { Jaekel, H.. }\end{array}$ & $\begin{array}{l}\text { The Dublo architecture } \\
\text { pattern for smooth } \\
\text { migration of business } \\
\text { information systems: An } \\
\text { experience report }\end{array}$ & $\times$ \\
\hline $\begin{array}{l}4 \\
4\end{array}$ & $\begin{array}{l}\text { I } \\
\text { C } \\
\text { S } \\
\text { E }\end{array}$ & $\begin{array}{l}2 \\
0 \\
0 \\
4\end{array}$ & Matinlassi, M. & $\begin{array}{l}\text { Comparison of software } \\
\text { product line architecture } \\
\text { design methods: COPA, } \\
\text { FAST, FORM, KobrA and } \\
\text { QADA }\end{array}$ & O \\
\hline $\begin{array}{l}4 \\
5\end{array}$ & \begin{tabular}{l|} 
I \\
C \\
S \\
E
\end{tabular} & $\begin{array}{l}2 \\
0 \\
0 \\
4\end{array}$ & $\begin{array}{l}\text { Caporuscio, M., } \\
\text { Inverardi, P., } \\
\text { Pelliccione, P. }\end{array}$ & $\begin{array}{l}\text { Compositional verification } \\
\text { of middleware-based } \\
\text { software architecture } \\
\text { descriptions }\end{array}$ & O \\
\hline $\begin{array}{l}4 \\
6\end{array}$ & $\begin{array}{l}\text { I } \\
\text { C } \\
\text { S } \\
\text { E }\end{array}$ & $\begin{array}{l}2 \\
0 \\
0 \\
4\end{array}$ & $\begin{array}{l}\text { Grechanik, M., } \\
\text { Batory, D., Perry, } \\
\text { D.E. }\end{array}$ & $\begin{array}{l}\text { Design of large-scale } \\
\text { polylingual systems }\end{array}$ & 0 \\
\hline $\begin{array}{l}4 \\
7\end{array}$ & $\begin{array}{l}\text { I } \\
\text { C } \\
\text { S } \\
\text { E }\end{array}$ & $\begin{array}{l}2 \\
0 \\
0 \\
4\end{array}$ & François, A.R.J. & $\begin{array}{l}\text { A hybrid architectural style } \\
\text { for distributed parallel } \\
\text { processing of generic data } \\
\text { streams }\end{array}$ & O \\
\hline $\begin{array}{l}4 \\
8\end{array}$ & $\begin{array}{l}\text { I } \\
\text { C } \\
\text { S } \\
\text { E }\end{array}$ & $\begin{array}{l}2 \\
0 \\
0 \\
4\end{array}$ & $\begin{array}{l}\text { Khare, R., Taylor, } \\
\text { R.N }\end{array}$ & $\begin{array}{l}\text { Extending the } \\
\text { REpresentational State } \\
\text { Transfer (REST) } \\
\text { architectural style for } \\
\text { decentralized systems }\end{array}$ & O \\
\hline $\begin{array}{l}4 \\
9\end{array}$ & $\begin{array}{l}\text { I } \\
\text { C } \\
\text { S } \\
\text { E }\end{array}$ & $\begin{array}{l}2 \\
0 \\
0 \\
4 \\
\end{array}$ & $\begin{array}{l}\text { Hong Yan, David } \\
\text { Garlan, Bradley } \\
\text { Schmerl, }\end{array}$ & $\begin{array}{l}\text { DiscoTect: A System for } \\
\text { Discovering Architectures } \\
\text { from Running Systems }\end{array}$ & $x$ \\
\hline $\begin{array}{l}5 \\
0\end{array}$ & $\begin{array}{l}\text { I } \\
\text { C } \\
\text { S } \\
\text { E }\end{array}$ & $\begin{array}{l}2 \\
0 \\
0 \\
4\end{array}$ & $\begin{array}{l}\text { Bas van der } \\
\text { Raadt,Jasper } \\
\text { Soetendal,Michiel } \\
\text { Perdeck,Hans van } \\
\text { Vliet }\end{array}$ & Polyphony in Architecture & $x$ \\
\hline $\begin{array}{l}5 \\
1\end{array}$ & \begin{tabular}{l|}
$\mathrm{I}$ \\
$\mathrm{C}$ \\
$\mathrm{S}$ \\
$\mathrm{E}$
\end{tabular} & $\begin{array}{l}2 \\
0 \\
0 \\
4\end{array}$ & $\begin{array}{l}\text { Ian Gorton, } \\
\text { Jereme Haack }\end{array}$ & $\begin{array}{l}\text { Architecting in the Face of } \\
\text { Uncertainty: An Experience } \\
\text { Report }\end{array}$ & $x$ \\
\hline
\end{tabular}

\section{5 むすび}

本論文では, 学術論文引用ネットワーク分 析において.クラスタリングにより同定され た各領域における主要論文の自動抽出につ いて試みた. 具体的には, 引用論文の発表年
数の分散について分析し, その結果をページ ランクアルゴリズムに応用することにより 各論文の重要度を算出した。 そして, 立堀ら が2004年に発表したソフトウエア・アーキテ クチャの研究分野の動向調査報告と比較検 証することにより, 専門家が手動で抽出した 主要論文をどこまで自動で抽出できるかに ついて検証した. その結果, 対象論文はすべ て本アルゴリズムにおいても主要な論文と して抽出できていた。つまり, 専門家が抽出 した論文を本アルゴリズムによって分析す ることにより, 主要な論文として自動で抽出 することができた. 今後は, 本アルゴリズム で自動抽出された論文のさらなる分析を行 い, 専門家が抽出した論文との比較検証をし ていきたいと考える。

\section{参考文献}

[1] Sma11, H. (2006). Tracking and predicting growth areas in science. Scientometrics, 68, 595-610 [2］松尾豊. (2008), , 学術俯瞰とウェブか らの情報抽出’,「イノベーション政策及び政 策分析手法に関寸る国際共同研究」成果報告 書No. 4, pp43-59

[3] Lawrence Page, Sergey Brin, Rajeev Motwani, Terry Winograd, 'The PageRank Citation Ranking: Bringing Order to the Web' , 1998

[4] 立堀道昭, 丸山宏, 小林真, Danie1 Yellin, 吉田尚志, 川井奈央, :ソフトウエ ア・アーキテクチャ研究動向の調査報告概要, 情報処理学会研究報告, 2005 